\title{
O POEMA E A METÁFORA
}

Wilton José Marques*

Meus olhos brasileiros sonhando exotismos,

Chega!

Meus olhos brasileiros se fecham saudosos. Minha boca procura a "Canção do exílio".

Como era mesmo a "Canção do exílio?

Eu tão esquecido de minha terra... Ai terra que tem palmeiras

Onde canta o sabiá!"

Carlos Drummond de Andrade,

Europa, França e Bahia.

$\mathrm{D}$ esde o seu aparecimento em Primeiros cantos (1846), a Canção do exílio, do poeta maranhense Antônio Gonçalves Dias, tornou-se uma unanimidade geral, elevando-se, de imediato, à condição de topos literário. Dotado de um ritmo envolvente e interiorizando-se fundo no imaginário popular brasileiro, o poema inaugurou um modo particular de representação da natureza tropical, contribuindo decisivamente para transformá-la numa espécie de metáfora nacional. A Canção de Gonçalves Dias pode ser vista como componente importante no processo de fabulação da imagem de país empreendido pelo discurso compromissado dos "homens cultos" do oitocentos brasileiro; ou, dito de outra forma, ela entranhou-se de tal modo na nossa cultura que Machado de Assis, ao discursar na inauguração do busto de Gonçalves Dias no Passeio Público do Rio de Janeiro, em junho de 1901, não teve dúvidas ao afirmar que a "Canção está em todos nós".

* Pós-doutorando IEL/Unicamp.

1 MACHADO DE ASSIS, J. M. Discurso. Revista da Academia Brasileira de Letras, v. 29, n. 68, p. 434-435, ago. 1927. 
Dentro desse contexto, a leitura do poema gonçalvino, como resultado direto da normatização da metáfora da natureza edênica como aquela que, ao lado do indianismo, melhor exprime a idéia de identidade coletiva, pode ajudar no entendimento da pressa romântica em criar uma literatura propriamente nacional. Funcionando como uma espécie de pórtico dos Primeiros cantos, para usar a mesma expressão que Alexandre Herculano se referiu às Poesias Americanas, ${ }^{2}$ a Canção do exílio foi composta em julho de 1843, ainda em Coimbra, onde o poeta estudava Direito, e, segundo Alexandre Henriques Leal - primeiro biógrafo de Gonçalves Dias -, entrava num dos capítulos do romance Memórias de Agapito Goiaba. ${ }^{3}$

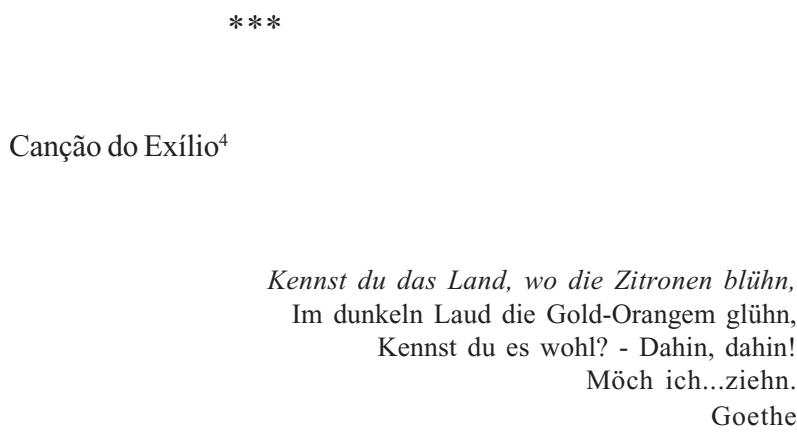

1. Minha terra tem palmeiras,

2. Onde canta o Sabiá,

3. As aves, que aqui gorjeiam,

4. Não gorjeiam como lá

5. Nosso céu tem mais estrelas,

2 Constituindo-se na primeira parte do livro de Gonçalves Dias, as Poesias Americanas, como o próprio nome já o sugere, são compostas por cinco poemas que procuram obviamente valorizar a terra e o índio locais. Os poemas que apareceram na primeira edição do livro são os seguintes: Canção do exílio; $O$ canto do guerreiro; $O$ canto do piaga; $O$ canto do índio e o Morro do Alecrim.

3 LEAL, A. H. Antônio Gonçalves Dias (notícia de sua vida e obras), Pantheon Maranhense. Lisboa: Imprensa Nacional, 1875. p. 34.

4 DIAS, A. G. Canção do exílio. In: BANDEIRA. M. (Ed.). Obras poéticas de Antônio Gonçalves Dias. Rio de Janeiro: Nacional, 1944. p. 21-22. Observação: A acentuação do poema foi atualizada segundo as normas do padrão culto vigente. 
6. Nossas várzeas têm mais flores,

7. Nossos bosques têm mais vida,

8. Nossa vida mais amores.

9. Em cismar - sozinho - à noite -

10. Mais prazer encontro eu lá;

11. Minha terra tem palmeiras,

12. Onde canta o Sabiá.

13. Minha terra tem primores,

14. Que tais não encontro eu cá;

15. Em cismar - sozinho - à noite -

16. Mais prazer encontro eu lá;

17. Minha terra tem palmeiras,

18. Onde canta o Sabiá.

19. Não permita Deus que eu morra,

20. Sem que eu volte para lá;

21. Sem que eu desfrute os primores

22. Que não encontro por cá;

23. Sem qu' inda aviste as palmeiras,

24. Onde canta o Sabiá.

Um primeiro contato com o texto de Gonçalves Dias e, logo, salta aos olhos a justeza encontrada pelo poeta maranhense na escolha da epígrafe que, retirada do romance de formação, Os Anos de Aprendizagem de Wilhem Meister, de Goethe, acomoda-se perfeitamente ao espírito da Canção do exílio. Ao escolher o fragmento da Balada de Mignon e assim traduzido por Manuel Bandeira: "Conheces o país onde florescem as laranjeiras? Ardem na escura fronde os frutos de ouro... Conhecê-lo? - Para lá, para lá quisera eu ir!",, Gonçalves Dias retira do poema original a expressão de um desejo que também vai percorrer a sua Canção, isto é, o desejo de voltar à Pátria. A figura de Mignon e de seu melancólico desejo transparecem algumas vezes no contexto do romance de Goethe: por exemplo, já quase no final do livro, observa-se a moça agonizando e o seu médico, vendo-se a sós com Wilhem, afirma a este que existem duas coisas que fazem a menina viver: "A natureza estranha dessa boa criança, de quem falamos agora, consiste exclusivamente numa profunda

5 BANDEIRA, op. cit., p. 22. 
nostalgia: o desejo louco de rever sua pátria, e o desejo pelo senhor, meu amigo, são, poderia mesmo dizer, os únicos elementos terrenos nela; ambos se tocam numa distância infinita; ambos são inacessíveis para essa alma singular" ${ }^{6}$

Se, por um lado, o drama da moça é marcado pela impossibilidade de realização de seu duplo desejo; por outro, o simples fato de o autor brasileiro ter recorrido ao referencial alemão exemplifica o diálogo constante que este, sempre ligado aos grandes temas, trava com a literatura européia. ${ }^{7}$ É possível perceber ainda que tanto no trecho do poema quanto no fragmento acima, o desejo de voltar é perpassado por uma forte nostalgia que, por sua vez, emblematiza a figura do expatriado. Portanto, a epígrafe da Canção do Exílio, apesar de Augusto Mayer questionar a liberdade com que Gonçalves Dias mutilou o poema original, ${ }^{8}$ apresenta, de antemão, dois dos motivos românticos que, juntamente com a metáfora da natureza, predominam no poema gonçalvino, ou seja, a incômoda sensação do sentir-se fora de lugar e a conseqüente melancolia que reveste a consciência do distanciamento da terra natal.

$$
* * *
$$

Apesar de o mote da Canção do Exílio já se mostrar evidente no seu próprio título, deve-se também, como subsídio à leitura, destacar com a devida atenção algumas características formais que permeiam a Canção e que escondem relações interessantes para o seu entendimento. Representante máximo do ufanismo brasileiro, o poema gonçalvino é composto por 24 versos distribuídos ao longo de suas cinco estrofes. Estas, por sua vez, são divididas em três quadras e duas sextilhas, com cada verso possuindo sete sílabas poéticas.

6 GOETHE, J. W. von. Os anos de aprendizagem de Wilhem Meister. São Paulo: Ensaio, 1994. p. 510. (sem grifos no original).

7 Gonçalves Dias nutria, por exemplo, uma profunda admiração pela literatura alemã, tanto que, durante o ano letivo de $1843 / 1844$, o poeta começou a estudar alemão para poder ler diretamente os poetas dessa língua. Em carta a Teófilo Leal, datada de 27 de agosto de 1843, ele escreve: "Se eu contasse um pouco mais comigo - por outra se eu soubesse grego e alemão - partia já para o Rio. Assim continuarei a escrever o meu poema - o meu romance e as minhas poesias soltas - estudarei alemão - e creio que um ano não será mal empregado". Cf. PEREIRA, L. M. A vida de Gonçalves Dias. Rio de Janeiro: J. Olympio, 1943. p. 50.

8 Cf. MAYER, A. Sobre uma epígrafe. In: __. A chave e a máscara. Rio de Janeiro: O Cruzeiro, 1964. p. 95-99. 
Entranhado na poética luso-brasileira, a redondilha maior, ou heptassílabo, é um metro ligado à tradição medieval-trovadoresca. A escolha desse tipo de verso, assim como também a escolha da canção, revela um gosto especial de Gonçalves Dias pela Idade Média. Essa preferência talvez se explique pelo fato de que tanto a redondilha quanto a canção tenham suas raízes na cultura popular e, enquanto preceito romântico, havia por parte dos autores a preocupação generalizada com o resgate de formas e motivos populares, como elementos da nacionalidade, em oposição aos motivos clássicos. Se ainda se pensar nas Volkslieder, de Herder, e as influências que tiveram na formação do pensamento romântico como um todo, a escolha de Gonçalves Dias ganha um caráter simbólico na medida em que seu poema, a exemplo das lieder alemãs, também está articulado com o projeto de diferenciação nacional, com a diferença óbvia de que aqui a Canção foi composta pelo poeta e, no caso alemão, as canções foram recolhidas junto à tradição medieval-popular.

Em relação ao aspecto rímico da Canção do Exílio, pode-se afirmar que este é construído de modo a realçar, através da sucessão obsessiva, a predominância da rima aguda (ou oxítona) em “a” (Sabiá, lá e cá). É curioso notar que existe uma visível articulação entre elas que provoca, também no nível rímico, uma valorização da terra natal em detrimento do exílio. Como facilmente se constata, as rimas agudas se reduzem a três e comutam de lugar de estrofe para estrofe: na 1. e e 3. , Sabiá e lá, na 4. . e 5. a, as duas anteriores e o cá. Observase que duas das rimas - cá e lá - constituem um par antitético clássico e se opõem diretamente nas duas últimas estrofes. Entretanto, o terceiro elemento rímico - Sabiá, que é algo particular à terra natal - provoca um desequilíbrio natural na tensão instalada entre as duas anteriores, acentuando sonoramente, no nível rímico, a predominância de elementos ligados à terra natal. Além disso, há nas duas últimas estrofes o aparecimento de uma rima muito sutil, e observada inicialmente por Manuel Bandeira, entre as palavras primores e palmeiras, com a primeira letra de cada sílaba coincidindo entre si. ${ }^{9}$

Finalmente, um outro aspecto formal a ser considerado é o ritmo. A estrutura rítmica da Canção do Exílio apresenta, atrás da simplicidade do heptassílabo, alguns diálogos que são fundamentais para a presente leitura. Como se sabe, o ritmo clássico da redondilha maior é o ritmo alternante, ou seja, aquele em que os versos se apresentam com acentuações na $1 .^{\mathrm{a}}, 3 .^{\mathrm{a}}, 5^{\mathrm{a}}$ e 7 . $^{\mathrm{a}}$

9 "Aproxime-se - afirma Bandeira - este verso [17] de 13 e nota-se a rima dos fonemas iniciais de 'primores' e 'palmeiras', repetida na estrofe seguinte; não intencional, é certo, mas achada pelo instinto do poeta e comunicando aos versos um dos elementos da sua inefável musicalidade." Cf. BANDEIRA, op. cit., p. 24, sem grifos no original. 
sílabas. Vejam-se estes dois exemplos: 1. Minha terra tem palmeiras; 2. Onde canta o Sabiá. Entretanto, no poema de Gonçalves Dias, esse ritmo não tem um comportamento uniforme, ocasionando mudanças, ao que parece propositais, na acentuação de alguns versos e, conseqüentemente, produzindo modificações importantes no andamento melódico do poema.

Atentando-se minuciosamente ao texto, é possível perceber que cinco versos se constituem numa exceção à regra do ritmo predominante. Esses versos (3, 14, 21, 22 e 23) podem ser divididos em dois grupos distintos: o primeiro, formado pelos versos 3, 14 e 22, com a acentuação recaindo na $2 .^{a}$ sílaba; e o segundo, formado pelos versos 21 e 23, com a acentuação recaindo na 4. ${ }^{a}$ sílaba. Vejam-se os grupos: o primeiro, (3. As aves que aqui gorjeiam; 14. Que tais não encontro eu cá; 22. Que não encontro por cá). Como inicialmente demonstrou José Guilherme Merquior ${ }^{10}$ e posteriormente complementou Adélia B. de Menezes, ${ }^{11}$ a referência explícita do poeta à terra alheia suscita a construção de um ritmo diferente. Ou seja, ao se aludir diretamente ao exílio, e denotando com isso uma intencionalidade em si, o poeta provoca uma mudança significativa no ritmo da canção, impondo "para terra estranha, um ritmo estranho". ${ }^{12}$

Já no segundo grupo (21. Sem que desfrute os primores; 23. Sem qu'inda aviste as palmeiras), a mudança de acentuação induz uma aproximação, já detectada anteriormente, entre primores e palmeiras. Esse dado aponta fortes indícios que evidenciam uma relação mais profunda, e aparentemente ofuscada, entre ambos. A mudança de ritmo nestes versos confere-lhe singularidade própria que, por sua vez, esconde pontos reveladores da articulação geral do poema.

$$
* * *
$$

Ao privilegiar a natureza tropical como metáfora primeira da representação nacional, a Canção do Exílio, de Gonçalves Dias, corporifica em si o tradicional projeto de edenização dessa mesma natureza. No afã de construir uma imagem idealizada, o poema recupera e normatiza o mito que envolveu o Brasil desde os

10 A observação sobre o ritmo feita por Merquior refere-se unicamente à alteração de acentuação no verso 3. cf. MERQUIOR, J. G. O poema do lá. In: J. G. A razão do poema. Rio de Janeiro: Civilização Brasileira, 1965. p. 41-50.

11 Cf. MENEZES, A. B. de. As canções do exílio - estudo comparativo. In: SECRETARIA DA EDUCAÇÃO/COORDENADORIA DE ESTUDOS E NORMAS PEDAGÓGICAS. Subsídios à proposta Curricular de Língua Portuguesa para o $1 .^{\circ}$ e $2 .^{\circ}$ Graus. São Paulo: Secretaria da Educação/CENP, 1987. p. 44-91.

12 MENEZES, op. cit., p. 49. 
primórdios de sua colonização: o do paraíso terreal. ${ }^{13}$ De presença viva na tradição ocidental e transladado do Oceano Índico para o Atlântico no período aventureiro das grandes navegações, a crença no paraíso foi alimentada por várias histórias e relatos. No caso específico do Brasil, o mito produziu fortes ressonâncias e um exemplo significativo, que comprova, inclusive, a persistência dessa crença em momentos bem posteriores à descoberta do país, encontra-se na seguinte passagem da História da América Portuguesa, de Sebastião da Rocha Pita, publicada em 1730, onde o autor afirma com todas as letras que o Brasil é o paraíso terral descoberto:

Em nenhuma outra região se mostra o céu mais sereno, nem madruga mais bela a aurora: o sol em nenhum outro hemisfério tem os raios tão dourados, nem os reflexos noturnos tão brilhantes: as estrelas são as mais benignas, e se mostram sempre alegres: os horizontes, ou nasça o sol, ou se sepulte, estão sempre claros: as águas, ou se tomem nas fontes pelos campos, ou dentro das povoações nos aquedutos, são as mais puras: enfim o Brasil terreal paraíso descoberto, onde tem nascimento, e curso os maiores rios; domina salutífero clima; influem benignos astros, e respiram auras suavíssimas, que o fazem fértil, e povoado de inumeráveis habitadores, posto que por ficar debaixo da tórrida zona, o desacreditassem, e dessem por inabitável Aristóteles, Plínio, Cícero. ${ }^{14}$

13 A esse respeito, escreve Sérgio Buarque de Holanda: "A idéia de que do outro lado do Mar Oceano se acharia, se não o verdadeiro Paraíso Terreal, sem dúvida um símile em tudo digno dele, perseguia, com pequenas diferenças, a todos os espíritos. A imagem daquele jardim deleitoso fixada através dos tempos em formas rígidas, quase invariáveis, compêndio de concepções bíblicas e idealizações pagãs, não se podia separar da suspeita de que esta miragem devesse ganhar corpo num hemisfério ainda inexplorado, que os descobridores costumam tingir de cores de sonho. E a suspeita conseguia impor-se até mesmo aos mais discretos e atilados, àqueles cujo espírito se formara no convívio assíduo com os autores da Antigüidade". Cf. HOLANDA, S. B. de. Paraíso perdido. In: Visões do Paraíso. Rio de Janeiro: J. Olympio, 1956. p. 201.

14 MOISÉS, M. A literatura brasileira através dos textos. São Paulo: Cultrix, 1974. p. 60. (sem grifos no original). 
Ao contrário dos excessos que caracterizam o texto de Rocha Pita, a Canção do Exílio, de Gonçalves Dias, é dotada de uma contenção própria que se revela, aos olhos do leitor atento, pela ausência de qualquer adjetivo. ${ }^{15}$ Assim, o problema que se coloca é o de mapear as relações internas que vicejam do poema e que, ao suscitarem o desejo de individuação nacional, se remetem, através da metáfora da natureza tropical, à figura imagética do paraíso terreal.

$$
* * *
$$

Inicialmente, a interpretação do poema será feita através da montagem de um esquema comparativo que é possível inferir a partir de características levantadas junto às duas primeiras estrofes e que estabelecem um confronto direto entre um cá menosprezado e um lá altamente valorizado:

1. Minha terra tem palmeiras,

2. Onde canta o Sabiá,

3. As aves, que aqui gorjeiam,

4. Não gorjeiam como lá.

5. Nosso céu tem mais estrelas,

6. Nossas várzeas têm mais flores,

7. Nossos bosques têm mais vida,

8. Nossa vida mais amores.

A primeira estrofe do poema apresenta elementos que são restritos ao lá, ou seja, palmeiras e Sabiá. Estes, por sua vez, formam uma espécie de campo de atributos exclusivos. Em contrapartida, a segunda estrofe apresenta, mediada por um mais providencial, um esquema implícito de comparações entre elementos comuns tanto ao cá quanto ao lá, caracterizando-se como um campo de atributos comuns.

15 Foi Aurélio Buarque de Holanda que, refletindo sobre o segredo da simplicidade do poema, chamou a atenção para a completa ausência de qualificativos neste. Cf. HOLANDA, A. B. de. À Margem da Canção do Exílio. In: HOLANDA, A. B. de. Território Lírico (Ensaios). Rio de Janeiro: O Cruzeiro, 1953. p. 23-32. 
Nas três estrofes seguintes, a Canção é marcada pela reiteração obsessiva dos termos exclusivos ao lá. A estes, associa-se a solidão, que é assimilada aqui como um meio através do qual o eu-lírico se apóia para reafirmar, a todo instante, a superioridade de sua terra em contraponto ao exílio. Essa reafirmação é embalada por um componente imprescindível da cisma romântica: a saudade, sentimento motriz que reveste o poema de uma dor nostálgica contida e, por isso, mais pungente.

Se, inicialmente, a preocupação era a de identificar e nomear os campos de atributos, agora, esta se desloca no sentido de se ater mais demoradamente na análise de cada um. Isso permitirá o estabelecimento dos pressupostos necessários para se pensar como a Canção do Exílio se constitui num projeto diga-se, bem sucedido - de idealização da terra natal e de, ao mesmo tempo, afirmação nacional.

No campo de atributos exclusivos existem, como já identificado, apenas dois elementos restritos ao lá: palmeira e Sabiá. ${ }^{16}$ Tanto o primeiro quanto o segundo aparecem, do ponto de vista numérico, quatro vezes no poema, confirmando a também mencionada reiteração obsessiva. Essa ocorrência deve ser interpretada com um certo cuidado. De certo modo, além da igualdade numérica, os dois termos se equivalem somente no plano físico e enquanto elementos exóticos e exclusivos à natureza do lá. Uma vez que o termo Sabiá não se restringe apenas à representação física de ave, ele a transcende. Grafado na Canção do Exílio em maiúscula, e por isso colocado, no contexto do poema, no mesmo plano de Deus, o Sabiá transita do espaço físico para o simbólico e viceversa, de maneira a representar ora a ave em si, aproximando-se de palmeiras, ora a voz superior da natureza brasileira, imagem simbólica da individuação nacional. Com este artifício dialético, todo o campo de atributos exclusivos é elevado metaforicamente à condição de símile do paraíso terreal.

No campo dos atributos comuns instaura-se um esquema comparativo, marcado pela presença do mais, entre elementos comuns tanto ao cá quanto ao

16 O uso simbólico da figura do sabiá, por parte de Gonçalves Dias, não era propriamente uma novidade na literatura brasileira. Mas foi com seu poema que a ave ganhou uma significação especial, assumindo, enquanto dado poético, uma posição semelhante à ocupada pelo rouxinol na literatura européia. Entretanto, no caso brasileiro, o sabiá tornouse marca de brasilidade. É nesse sentido que Justiniano José da Rocha, ao comentar o primeiro livro de poemas de Gonçalves de Magalhães - Poesias (1832) - afirma que "o Sabiá Brasiliense já desentronizou o rouxinol d'Europa, e algumas das belezas americanas trajaram as ricas galas da Poesia". Cf. ROCHA, J. J. da. Ensaio crítico sobre a coleção de poesia do Sr. D. J. G. de Magalhães. In: CASTELO, J. A. (Org.). Textos que interessam à história do romantismo. São Paulo: Conselho Estadual de Cultura, 1963. v. 2. p. 38-44. 
lá. No entanto, os atributos da terra natal do eu-lírico - estrelas, flores, bosques etc. - são apresentados de forma diferenciada, justificada apenas por sua localização espacial. O simples fato de pertencerem ao lá lhes dá um caráter aurático que encontra a sua justa representação em primores.

De fato, pode-se afirmar que, na realidade, todos os elementos, inclusive os comuns ao cá, expressam a idéia do paraíso terral. Essa perspectiva fica evidente na síntese em primores dos chamados atributos comuns. Além da própria significação etimológica de primores - o que ocupa o primeiro lugar - a síntese se dá no nível estrutural do poema, sendo demonstrada pela recuperação de ordem rímica. Na segunda estrofe da Canção do Exílio, os versos 6 e 8, curiosamente os únicos versos pares em que não ocorre rima aguda em $a$, terminam respectivamente com as palavras flores e amores. Esse dado aponta para uma relação singular, ou seja, ao recuperar a rima em ores no verso 13 , o termo primores atrai a segunda estrofe de modo a sintetizar em si os principais atributos do lá, em detrimento dos atributos de cá.

Partindo da perspectiva em que os atributos comuns se abrigam sob a sombra sintética de primores, chega-se à articulação derradeira, cujo ponto nevrálgico consiste no desvendamento da intensa relação que existe entre primores e palmeiras. Há, aí, uma correspondência velada que ofusca a completa idealidade do lá. No limite das significações, ocorre a fusão simbólica entre os dois termos, transformando, dessa feita, os atributos, sintetizados em primores, e que pareciam comuns ao cá, em atributos idealizados e exclusivos ao lá.

Se comprovada, essa fusão simbólica entre palmeiras e primores reforça a tese de que a terra natal do eu-lírico é um lugar idealizado, já que, como se viu, o campo dos atributos exclusivos, ao ser permeado pela relação Sabiá/palmeiras, traduz o caráter edênico da natureza brasileira.

Então, nesse sentido, veja-se, inicialmente, os versos 13 e 17: 13. Minha terra tem primores; 17. Minha terra tem palmeiras. Ao se confrontarem estes dois versos, observa-se grande semelhança entre ambos, diferenciados apenas pelas palavras finais que, por sua vez, possuem afinidades entre si. Os versos apresentam um andamento rítmico idêntico e uma relação rímica peculiar entre primores e palmeiras. Esse tipo de rima sutil - a dos fonemas iniciais - foi usado algumas vezes por Gonçalves Dias e, apesar de Manuel Bandeira afirmar que elas aparecem de maneira espontânea e não intencional, é inevitável discordar do poeta modernista e da possibilidade do acaso, pois há uma intencionalidade patente e visível por trás da coincidência formal que reside justamente na quase equivalência dos versos. Essa proximidade entre os termos produz algo mais que a mera equivalência ou homologia. Há tal força de atração entre primores e 
palmeiras que os dois termos acabam se amalgamando numa representação única.

Essa tese se reforça, quando se observam os versos 21 e 23, nos quais há uma mudança de ritmo: 21. Sem que desfrute os primores, 23. Sem qu'inda aviste as palmeiras. Nestes dois versos, a acentuação se desloca para a 4. ${ }^{a}$ sílaba poética, induzindo o aparecimento de um ritmo que foge aos padrões normais, dando-lhes um andamento melódico único que os faz diferenciar dos demais. A variação rítmica acentua ainda mais a ligação entre primores e palmeiras. Dessa maneira, a intencionalidade dessa relação é patente, pois existe sempre uma particularidade que marca e destaca o caráter único dessa mesma relação: seja a semelhança dos versos 13 e 17, seja na mudança de ritmo dos versos 21 e 23.

Configurando-se a intensidade que envolve a ligação entre primores e palmeiras, pode-se reafirmar que, no limite, todos os atributos do lá são não somente exclusivos como também idealizados. A fusão simbólica entre os dois termos, inclusive sustentada por evidências estruturais de ordem rímica e rítmica, remete a Canção do Exílio e a sua conseqüente celebração do Brasil ao mito do paraíso terreal. A imagem da natureza edênica ganha com o poema uma significação maior na medida em que o poeta lança mão da sua condição de exilado para melhor compreender o país. O distanciamento da terra, condição necessária para o processo de idealização, permite ao poeta se colocar num lugar privilegiado que facilita a escolha de parâmetros de comparação, já que este pode - para melhor representá-la - lançar, de fora, um olhar idealizado sobre sua terra natal.

$* * *$

Ocupando um papel fundamental no projeto romântico local, a Canção do Exílio ampara-se, além da metáfora, em outro motivo que, como se viu, é igualmente importante para a valorização da terra natal, isto é, o olhar distanciado da realidade local. Em conseqüência disso, e agora amalgamada ao sentimento do exílio, a natureza brasileira atingiu com a Canção do Exílio uma dimensão única, elevando-se à condição diferenciada de símbolo da nossa nacionalidade. As palmeiras, ${ }^{17}$ o sabiá, as nossas estrelas, os nossos bosques - que, inclusive, mais tarde seria incorporado à letra do hino nacional -, cantados pelo poema,

17 Dentro do Romantismo, o caráter simbólico de palmeiras constitui um capítulo particular. Por isso não deixa de ser sintomático que, no final de $O$ Guarani, José de Alencar utilize a palmeira para salvar Peri e Ceci da inundação do rio Paraíba. 
ganharam um valor simbólico que, de imediato, caiu no gosto popular brasileiro. Isto talvez explique o fato de ter sido publicado, em janeiro de 1848, no jornal Correio da Tarde, uma das primeiras paródias do texto gonçalvino:

\author{
Minha terra tem silvados \\ Onde canta o rouxinol, \\ Onde canta a toutinegra \\ E o cuco no pôr do sol. \\ Qu'estrelas que por lá vão! \\ Que flores de cor subida! \\ Que vida naqueles bosques! \\ Que amores naquela vida! \\ Em cismar sozinho à noite \\ Que prazer eu tinha lá! \\ Minha terra é um paraíso, \\ Que não encontro por cá! ${ }^{18}$
}

O fragmento desta primeira paródia da Canção do Exílio deve ser visto como um dado indicativo do sucesso alcançado pelo poema gonçalvino que, com o passar dos tempos, foi se tornando o grande paradigma da nacionalidade literária do Brasil. Divisando uma voz própria, o poema se constituiu num topos recorrente com o qual quase todos os poetas, posteriores a Gonçalves Dias, dialogaram intensamente ao se referirem à cor local: seja explicitando um olhar otimista sobre o país, como no caso das canções de um Casimiro de Abreu; ${ }^{19}$ seja sofrendo uma releitura crítica, como a dos modernistas Oswald de Andrade, Carlos Drummond de Andrade, Murilo Mendes e, mais tarde, as de José Paulo Paes e Cacaso, ${ }^{20}$ a força do poema gonçalvino é tal que, inclusive, exerceu - num

18 Segundo Lúcia Miguel Pereira, "Publicada no Correio da Tarde de 5/01/1848, essa versalhada, que continua no mesmo tom, com uma dedicatória visivelmente destinada a bulir com algum figurão - coisa tão do gosto dos jornais do tempo - só tem o valor de mostrar a repercussão dos versos de Gonçalves Dias." Cf. PEREIRA, op. cit., p. 99, sem grifos no original.

19 Canção do exílio (1855) e Canção do exílio (1857).

20 Os poemas são respectivamente: Canto do regresso à pátria, Nova canção do exílio, Canção do exílio, Canção do exílio facilitada e Jogos florais. 
contra fluxo - influência sobre a literatura portuguesa. Num cancioneiro popular do século passado, descoberto por Beatriz Berrini, há uma "resposta" de um português à "mimosa poesia do célebre poeta brasileiro". O texto do poeta Estevão d'Araújo V. Pereira e Alvim, conservando a redondilha maior, introduz basicamente a mudança das referências locais sabiá e palmeiras por respectivamente rouxinol e colinas:

Minha terra tem colinas

Onde canta o rouxinol

Não permita deus que eu morra

Sem que eu veja o seu farol,

Suas tão belas campinas,

Seu doce pôr do sol;

Sem que pise inda as colinas

Onde canta o rouxinol. ${ }^{21}$

Em suma, tanto as paródias locais quanto a "resposta portuguesa" dão indícios claros da persistência poética da Canção do exílio e de sua importante contribuição para o delineamento da literatura nacional. Na verdade, o poema de Gonçalves Dias, ao também se apoiar em sentimentos universais como a dor do exílio, não somente se tornou um referencial paradigmático de louvor à brasilidade através da perpetuação da imagem da natureza edênica, mas, sobretudo, fundou por si uma tradição na literatura brasileira que, ainda hoje, encontra ecos.

\section{RESUMO}

Este ensaio tenta provar que a Canção do Exílio, de Gonçalves Dias, ao privilegiar a natureza tropical como metáfora da representação nacional, além de se inserir no tradicional projeto de edenização da natureza local, por si só acabou construindo uma tradição própria dentro das letras brasileiras.

21 Cf. BERRINI, B. Presença de Gonçalves Dias no Portugal oitocentista. Estudos Portugueses e Africanos, Campinas, n. 23, p. 31-48, jan./jun. 1994. 
Palavras-chave: Romantismo, Literatura Brasileira, Antônio Gonçalves Dias, 1823-1864.

\section{ABSTRACT}

This essay tries to give proof that the Canção do Exílio, by Gonçalves Dias, in privileging the tropical nature as a metaphor for the national representation, besides placing itself in the traditional project of mythfication of the local nature, by itself ended up building its own tradition in the Brazilian literature.

Key-words: Romanticism, Brazilian literature, Antônio Gonçalves Dias, 18231864.

\section{REFERÊNCIAS}

BERRINI, B. Presença de Gonçalves Dias no Portugal oitocentista. Estudos Portugueses e Africanos, Campinas, n. 23, p. 31-48, jan./jun. 1994.

DIAS, A. G. Canção do exílio. In: BANDEIRA. M. (Ed.). Obras poéticas de Antônio Gonçalves Dias. Rio de Janeiro: Nacional, 1944.

GOETHE, J. W. von. Os anos de aprendizagem de Wilhem Meister. São Paulo: Ensaio, 1994.

HOLANDA, A. B. de. À Margem da Canção do Exílio. In: Território Lírico (Ensaios). Rio de Janeiro: O Cruzeiro, 1953.

HOLANDA, S. B. de. Paraíso perdido. In: . Visões do Paraíso. Rio de Janeiro: J. Olympio, 1956.

LEAL, A. H. Antônio Gonçalves Dias (notícia de sua vida e obras), Pantheon Maranhense. Lisboa: Imprensa Nacional, 1875.

MACHADO DE ASSIS, J. M. Discurso. Revista da Academia Brasileira de Letras, v. 29, n. 68 , p. 434-435, ago. 1927.

MAYER, A. Sobre uma epígrafe. In: A chave e a máscara. Rio de Janeiro: $\mathrm{O}$ Cruzeiro, 1964. 
MENEZES, A. B. de. As canções do exílio - estudo comparativo. In: SECRETARIA DA EDUCAÇÃO/COORDENADORIA DE ESTUDOS E NORMAS PEDAGÓGICAS. Subsídios à proposta Curricular de Língua Portuguesa para o $1 .^{\circ}$ e 2. ${ }^{\circ}$ Graus. São Paulo: Secretaria da Educação/CENP, 1987.

MERQUIOR, J. G. O poema do lá. In: A razão do poema. Rio de Janeiro: Civilização Brasileira, 1965.

MOISÉS, M. A literatura brasileira através dos textos. São Paulo: Cultrix, 1974.

PEREIRA, L. M. A vida de Gonçalves Dias. Rio de Janeiro: J. Olympio, 1943.

ROCHA, J. J. da. Ensaio crítico sobre a coleção de poesia do Sr. D. J. G. de Magalhães. In: CASTELO, J. A. (Org.). Textos que interessam à história do romantismo. São Paulo: Conselho Estadual de Cultura, 1963. 